\title{
Characterization of volatiles in red- and white-fleshed loquat (Eriobotrya japonica) fruits by electronic nose and headspace solid-phase microextraction with gas chromatography-mass spectrometry
}

\author{
Haiyan SUN ${ }^{1}$, Weiwei $\mathrm{CHEN}^{1}$, Yun JIANG ${ }^{1}$, Qiao $\mathrm{HE}^{1}$, Xiaolin $\mathrm{LI}^{1}$, Qigao GUO ${ }^{1}$, Suqiong XIANG ${ }^{1}$, \\ Wanpeng $\mathrm{XI}^{1}$, Guolu LIANG ${ }^{1 *}$
}

\begin{abstract}
Aroma differences are generally sensed in white- and red-fleshed loquats. Here, volatile compounds in four white- and three red-fleshed loquat varieties were investigated by headspace solid-phase microextraction and combined analysis of electronic nose (e-nose) and gas chromatography-mass spectrometry (GC-MS). In total, 83 volatile compounds were identified, and 33 were common in all of the cultivars. D-limonene, hexanal, (E)-2-hexenal, octanal and nonanal were the most abundant volatile compounds. $\beta$-cyclocitral and $\beta$-ionone were only detected in red-fleshed varieties. Furthermore, Huayu Seedless 1 (triploid white-fleshed loquats) with low levels of terpenoid compounds detected by GC-MS were clearly differentiated from the other cultivars tested by principal component analysis (PCA), which was consistent with the e-nose results. PCA analysis showed that Huabai 1(white flesh cultivar)had a prominent volatile profile characterized by higher concentrations of C6 aldehydes and alcohols, (E)-2-hexanal, (Z)-3-hexenal and hexanal, (Z)-3-hexenol, (E)-2-hexenol and hexanol. In comparison with red-fleshed loquats, white-fleshed loquats were characterized by high aldehydes content. These volatile compounds served to recognize and classify all of the analysed varieties.
\end{abstract}

Keywords: loquat; volatile compounds; electronic nose; GC-MS.

Practical Application: Compared the similarities and differences between white-fleshed varieties and red-fleshed ones and provided a useful tool for the selection of cultivar breeding and the improvement of loquat fruit quality.

\section{Introduction}

Loquat (Eriobotrya japonica Lindl.) is a subtropical evergreen fruit tree of the family Rosaceae. It has been widely cultivated in many countries, especially in China, Japan, India, Turkey, Pakistan, Spain, the United States, and Australia (Wu et al., 2015). Loquat fruit is consumed largely as fresh fruit due to its excellent flavour, plentiful nutritional values, and medical applications. The volatile compounds, which are produced by the fruit, create aroma, contribute to flavour, and strongly impact the fruit quality and value. The volatile composition of the fruit provides the consumer with a good indicator of quality and attracts consumers to purchase the fruit (Forney, 2001). Recently, the relative contributions of specific aromatic volatile compounds to the flavour of loquats has been examined by many investigators and more than 100 volatile compounds have been identified (Shaw \& Wilson, 1982; Fröhlich \& Schreier, 1990; Hideki et al., 1998; Takahashi et al., 2000; Pino et al., 2002; Chen et al., 2011; Besada et al., 2013; Jiang et al., 2014; Besada et al., 2017; Yuan et al., 2018). The major portion of these volatiles consists of alcohols, aldehydes, esters, terpenoids, ketones, acids and alkanes.

E-nose is an instrument that mimics smell sense to detect and distinguish volatiles in complex samples (Peris \& Escuder-Gilabert, 2009). E-nose sensors do not require chemical reagents, have good sensitivity and specificity, provide rapid results, and allow for the non-destructive sampling of odourants or analytes (García-González \& Aparicio, 2002). For these reasons, there has been great interest in the development of electrochemical receptors for detecting aromas of complex vapour mixtures (Wilson \& Baietto, 2009). Headspace solid phase microextraction (HS-SPME) integrated with GC-MS has become an established method, owing to its solvent-free sample processing, sensitivity, reliability and potential to identify analysed compounds in conjunction with an adequate detector (Reinhard et al., 2008), and has been widely used in plant research (Barboni et al., 2009; González-Mas et al., 2011).

The colour of fruits of loquat cultivars varies from yellow to orange-red in the peel and white to orange in the flesh. Loquat cultivars are usually sorted into white- and red-fleshed groups according to the flesh colour (Zhou et al., 2007; Fu et al., 2012, 2014; Liu et al., 2016). In this study, through combining e-nose and SPME with GC-MS, we investigated the pulp volatiles of four white-fleshed loquat varieties and three red-fleshed ones at ripening. The aim of this work was to determine the aroma compounds responsible for similarities and differences between white-fleshed varieties and red-fleshed ones and to provide a useful tool for the selection of cultivar breeding and the improvement of loquat fruit quality.

${ }^{1}$ Key Laboratory of Horticulture Science for Southern Mountainous Regions, Ministry of Education, College of Horticulture and Landscape Architecture, Southwest University, Chongqing, People's Republic of China

*Corresponding author: lianggl@swu.edu.cn 


\section{Materials and methods}

\subsection{Plant materials}

Seven different varieties of loquat (Table 1) were used to study e-nose and aroma composition and content in 2013 and 2015 from an orchard for breeding and germplasm conservation in Beibei (Chongqing, China). The fruits were harvested in a state of commercial maturity. Once in the laboratory, twelve fruits were further selected at a relatively uniform level of maturity and divided into three groups of four fruit. Pulps were cut into small pieces after removal of the peel and frozen with liquid $\mathrm{N}_{2}$. Then, samples of each group were pooled together and kept at $-80{ }^{\circ} \mathrm{C}$ for further analysis.

\subsection{Electronic nose analysis}

A FOX 4000 from MOS (Alpha, Toulouse, France) was used as the electronic nose system. The instrument was equipped with 18 metal oxide sensors. Frozen pulp powder $(1 \mathrm{~g})$ and saturated sodium chloride solution $(5 \mathrm{~mL})$ were mixed by a vortex mixer in a $10 \mathrm{~mL}$ plastic tube, and $2 \mathrm{~mL}$ homogenate solution were transferred to a $10 \mathrm{~mL}$ glass vial and sealed with cover gaskets. The samples were heated to $40{ }^{\circ} \mathrm{C}$ for $30 \mathrm{~min}$, and $2 \mathrm{~mL}$ of headspace air was then injected into the equipment by a syringe. The response phase was recorded for $120 \mathrm{~s}$, and the clean phase lasted for $240 \mathrm{~s}$. The electronic nose analysis was carried out on three replicates at the given sampling time.

\subsection{Volatiles analysis}

The measurements were determined according to the method of Zhang et al. (2009) and Azam et al. (2013) with modifications. Frozen pulp powder samples $(5 \mathrm{~g})$ were placed in a $20 \mathrm{~mL}$ glass vial and $5 \mathrm{~mL}$ of saturated sodium chloride solution were added. The extraction of volatile compounds was carried out by manual headspace solid phase microextraction using a fibre (Supelco Co., Bellefonte, PA, USA) coated with $65 \mu \mathrm{m}$ polydimethylsiloxane and divinylbenzene; samples were equilibrated at $40{ }^{\circ} \mathrm{C}$ for $30 \mathrm{~min}$ and then exposed for $30 \mathrm{~min}$. An Agilent $7890 \mathrm{~N}$ series gas chromatograph with an Agilent 5973C mass spectrometer was used. The volatile compounds were separated with a DB-WAX column $(0.25 \mathrm{~mm}, 30 \mathrm{~m}, 0.25 \mathrm{wm}$, J\&W Scientific, USA). The oven temperature was programmed as follows: injector $240^{\circ} \mathrm{C}$, run at $40^{\circ} \mathrm{C}$ for $2 \mathrm{~min}$, ramped up to $150^{\circ} \mathrm{C}$ at a rate of $3{ }^{\circ} \mathrm{C} / \mathrm{min}$ and held for $2 \mathrm{~min}$, again ramped up to $220^{\circ} \mathrm{C}$ at a rate of $10^{\circ} \mathrm{C} / \mathrm{min}$ and held for $2 \mathrm{~min}$. Helium was used as the carrier gas at $1.0 \mathrm{~mL} \mathrm{~min}^{-1}$. GC-MS was operated with an electron ionization of $70 \mathrm{eV}$ and ion source temperature of $230^{\circ} \mathrm{C}$. Compounds were tentatively identified by comparing mass spectra with those of the data system library (NIST 08) (National Institute of Standards and Technology, Washington, DC, USA) (Capone at al., 2013) and with retention indices (RI) and references (Shaw \& Wilson, 1982; Fröhlich \& Schreier, 1990; Pino et al., 2002; Chen et al., 2011; Besada et al., 2013, 2017; Jiang et al., 2014). Retention indices were calculated using a mixture of n-alkane (C7-C30) as standards. Quantitative analysis was conducted using as ethyl nonanoate as an internal standard. The concentrations of volatile components were expressed as $\mu \mathrm{g} / \mathrm{g}$ FW(Fresh Weight).

\subsection{Statistical analysis}

Data from the electronic nose were analysed using principal component analysis (PCA) in Alpha soft (version 11.0). Volatile compound data were analysed as the mean values \pm standard deviation (SD) of three replicates. Analysis of variance (ANOVA) for mean comparisons (Tukey, 5\% probability) were performed. For volatile compound PCA, the complete dataset including all replicates was considered. PCA analyses were performed with JMP version 13.0 for Windows (SAS Institute Inc., NC, USA). PCA based on correlations was applied to differentiate loquat cultivars using the content value of volatiles. Data set was organized onto a matrix constituted by 7 or 6 cultivars of loquat and 83 variables (the identified volatile components).

\section{Results and discussion}

\subsection{Discrimination of loquat varieties of principal component analysis by e-nose}

The PCA was carried out using pulp volatiles of e-nose measurements from the seven cultivars (Figure 1A). The percent of total variance of the first two PCs was $99.45 \%$. PC1 represented $98.27 \%$ of the variance and PC2 represented $1.18 \%$ of the variance. HYS1 is a natural triploid loquat, HYS1 and the other six cultivars were clustered into two distinguished groups based on their pulp volatiles profile as measured by the e-nose. All of the other six cultivars were discerned from each other, however, slight overlaps occurred at the CB1 and HB1. After removing data from HYS1 cultivar, examining PCA results, the first principal components allowed a good discrimination between XZ, CB1, HB1 and other three cultivars. The second principal components can clearly separate white flesh loquats-- RTBS from red flesh loquats LQ1, XZ (Figure 1B). PCA with seven cultivars could not separate white-fleshed and red-fleshed loquats, but discerned triploid

Table 1. Loquat cultivars included in the pulp volatile study.

\begin{tabular}{|c|c|c|c|c|}
\hline & Cultivars & Abbreviations & Pulp colour & Origin from \\
\hline 1 & Huayuseedless 1 & HYS 1 & White & Changbai 1 seedling seed \\
\hline 2 & Changbai 1 & CB 1 & White & Seedling tree \\
\hline 3 & Ruantiaobaisha & RTBS & White & Not detailed \\
\hline 4 & Huabai 1 & HB 1 & White & Ruantiaobaisha seedling seed \\
\hline 5 & Jinhua 1 & JH 1 & Red & Longquan1 seedling seed \\
\hline 6 & Longquan1 & LQ 1 & Red & Seedling tree \\
\hline 7 & Xiangzhong & $\mathrm{XZ}$ & Red & Xiangtian $\times$ Jiefangzhong \\
\hline
\end{tabular}



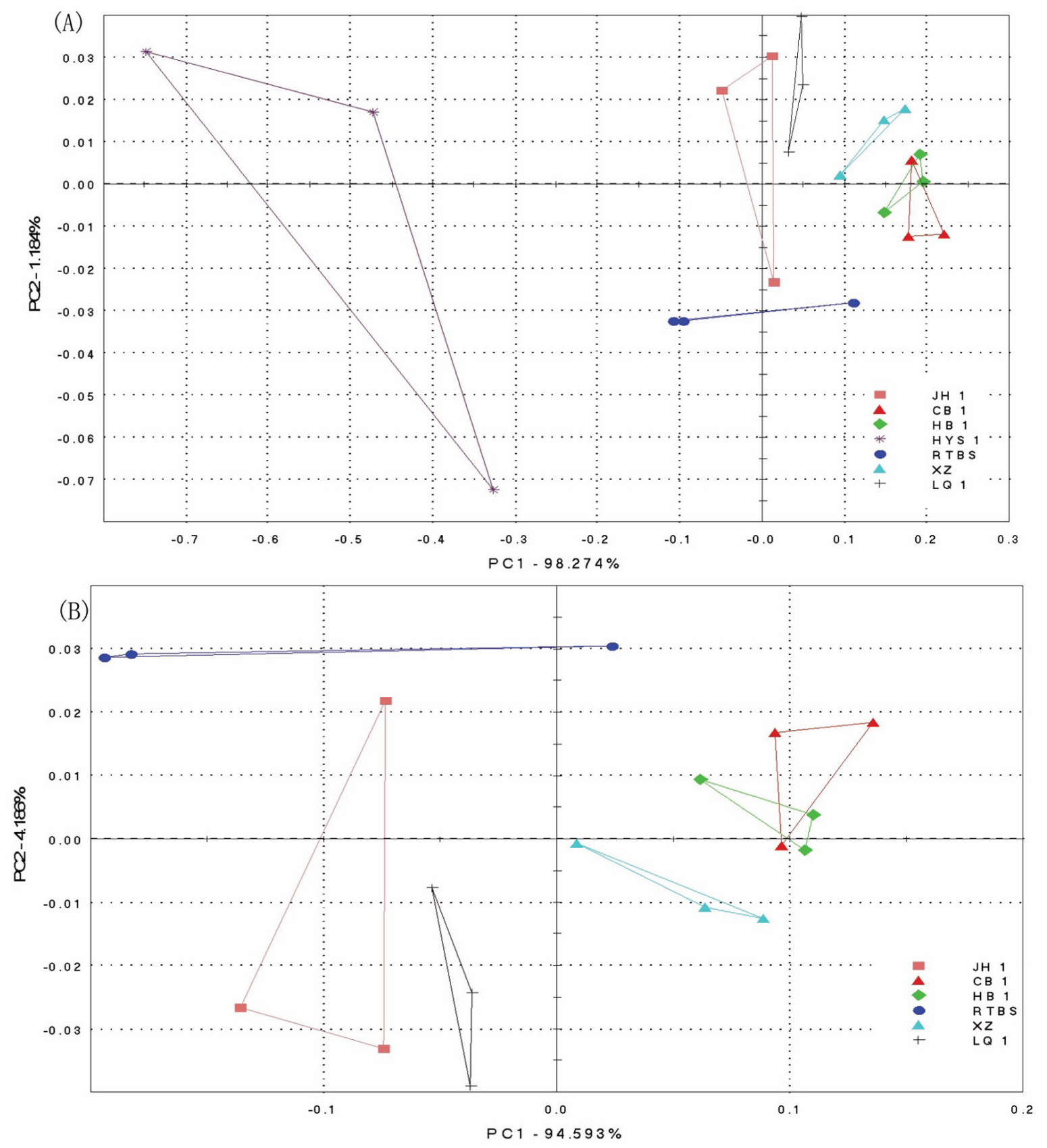

Figure 1. (A) Discrimination by PCA of 7 loquat cultivars and (B) PCA plot of 6 cultivars according to pulp volatile compounds measured by e-nose. HYS1, CB1, HB1 and RTBS were white-fleshed cultivars, while JH1, LQ1 and XZ were red-fleshed one, as indicated in Table 1.

loquat HYS1 from other diploid loquats. The e-nose allowed for the identification of mixtures of organic samples as a whole (Wilson \& Baietto, 2009). It might be that HYS1 contained fewer terpenoids and lower contents in comparison with the other varieties. Not all cultivars were discerned completely from other cultivars, and this result was consistent with the results of Su et al. (2013) and Solis-Solis et al. (2007). Although e-nose technique based on multivariate analysis does not give exact information about the different volatile compounds, the main advantage of this method over the GC-MS analysis is, without doubt, the shorter analysis time (Capone et al., 2013).

\subsection{Identification of volatile compounds}

By using HS-SPME coupled with GC-MS, a total of 83 volatile compounds were identified in the seven loquat cultivars. These compounds included 20 aldehydes, 20 alcohols, 13 terpenoids, 2 acids, 7 ketones, 12 esters and 9 other compounds. The volatile compound content in pulps of the seven different loquats is summarized in Table 2. Aldehydes, alcohols, terpenoids and esters were the most numerous groups with populations of $20,20,13$ and 12 compounds, respectively, and these were considered to be important flavour determinants. Among them, 33 volatile compounds were detected in all varieties. 


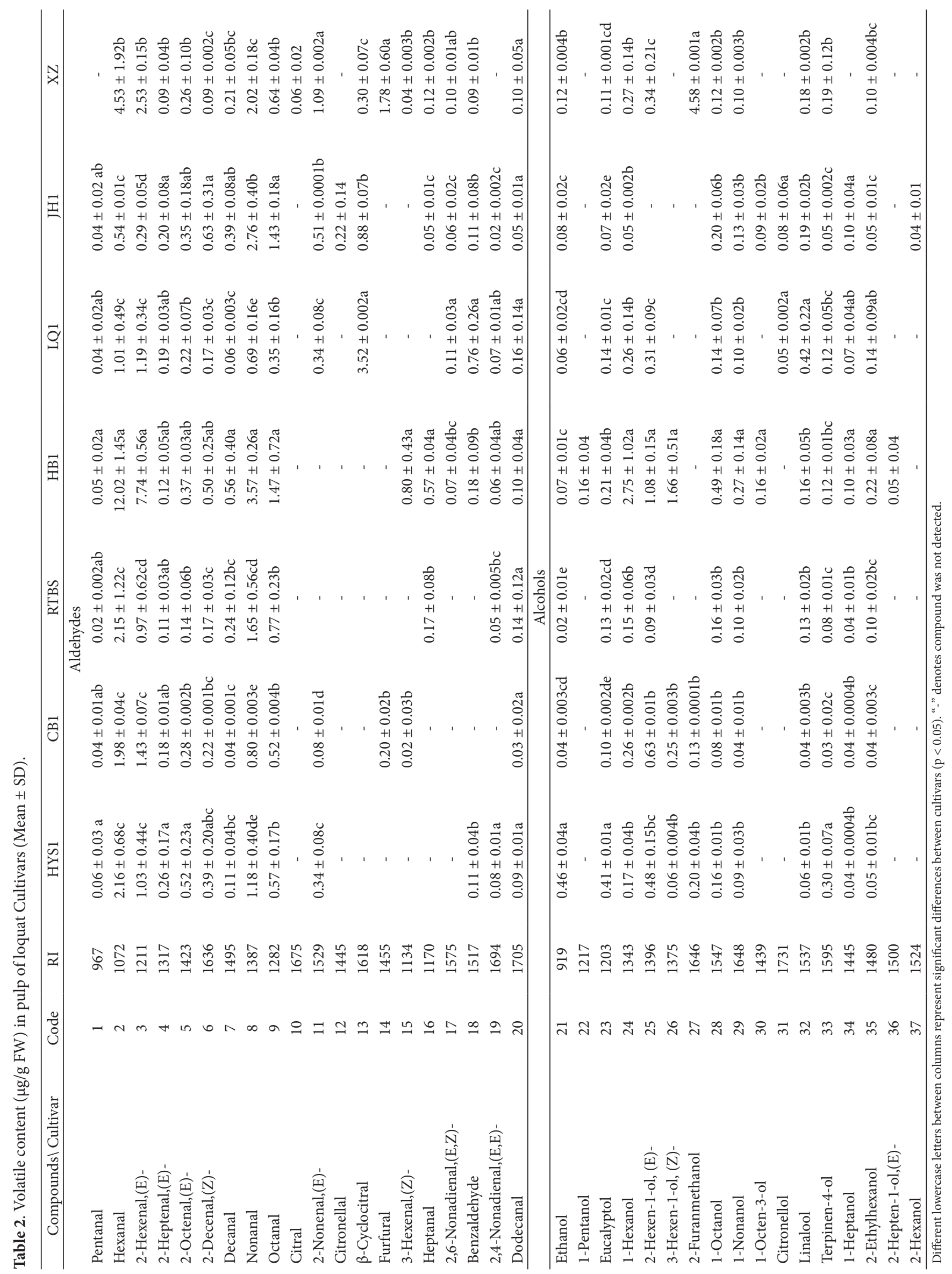


Sun et al.

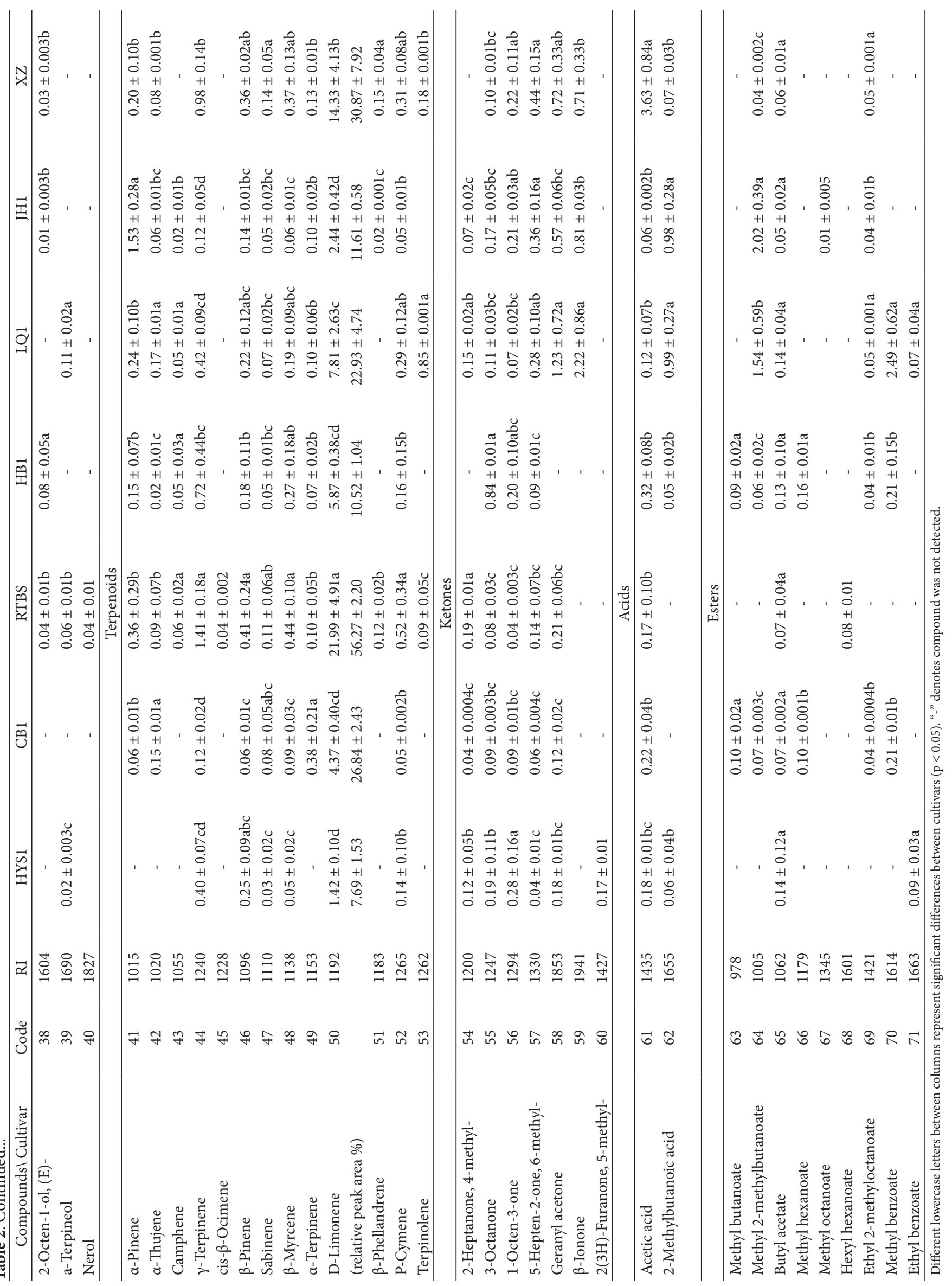




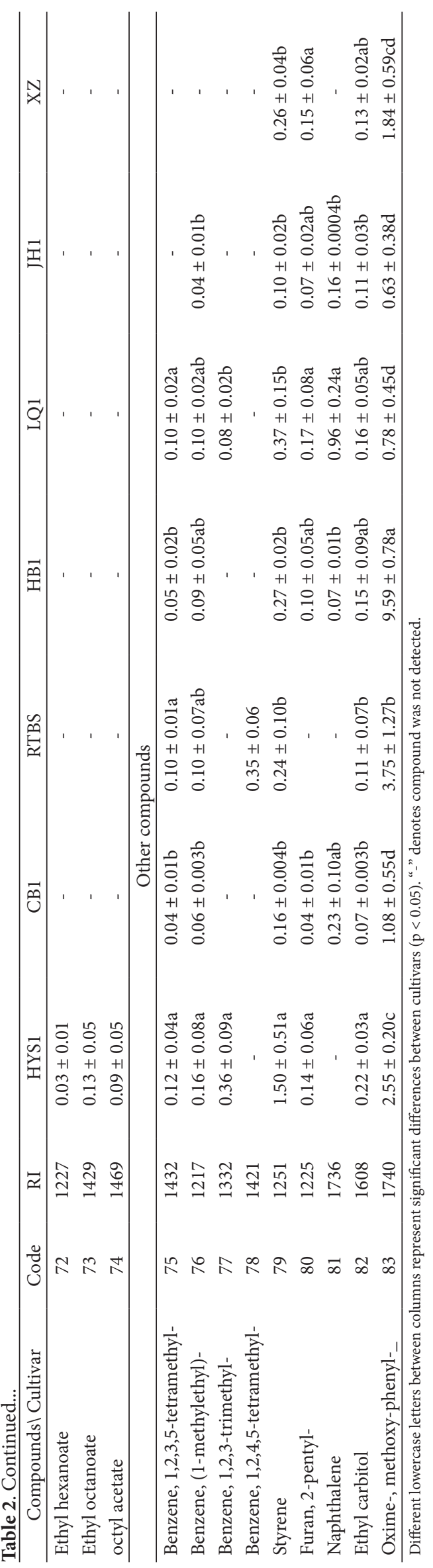


Among these terpenoids, D-limonene was the most abundant compound, which accounted for $7.69-56.27 \%$ of the total aromatic volatiles. A similar high content of D-limonene in the other loquat cultivars was also observed. Jiang et al. (2014) found that the percentage of D-limonene accounted for approximately $62.59-68.32 \%$ in Xiangtian, Jiefangzhong, Xiangzhong No.11 and Zhongxiang No.25. Pino et al. (2002) detected that limonene was an important constituent in loquat flavour. Limonene has an orange-like, fruity odour (Ren et al., 2015). Limonene was the primary component in orange juice flavour, but it was not the most important compound in flavour quality (Jia et al., 1998). The other major terpenoid compounds present in samples were $\gamma$-terpinene and $\alpha$-pinene. Six terpenoid compounds were detected in HYS1, and volatile content of HYS1 was lower than in the other loquat varieties. Only in RTBS was cis- $\beta$-ocimene present and, therefore, this compound might be more cultivar-specific.

Aldehydes were also dominant volatiles in loquat fruit. The most abundant volatile aldehyde component was hexanal with a green-type odour. (E)-2-hexenal had a green-type flavour and was another important aldehyde in loquat fruit. Fröhlich \& Schreier (1990) reported that hexanal, (E)-2-hexenal and benzaldehyde were major volatile compounds in Spanish loquat fruit. However, the most potent aromatic compound in fresh Japanese loquat (Tanaka) was phenylacetaldehyde. Other aromatic compounds, including hexanal and (E)-2-hexenal, may play important roles in fresh loquat aroma (Takahashi et al., 2000). Our results are in agreement with those of Fröhlich \& Schreier (1990) and Takahashi et al. (2000). The C6-aldehydes that derive from the lipoxygenase (LOX) pathway, such as (E)-2-hexanal, (Z)-3-hexenal and hexanal, a significantly higher contents were found in $\mathrm{HB} 1$ than in other six cultivars, $\mathrm{JH} 1$ had a volatile profile characterized by low levels of these aldheydes. (E)-2-hexanal, 2-hexenal, (Z)-3-hexenal and hexanal were detected with markedly higher levels in 'Raúl' loquats than in the other three cultivars (Besada et al., 2017). The aliphatic aldehydes such as octanal and nonanal were main constituents found in loquat fruit. Citronellal was only detected in $\mathrm{JH} 1$, and citral was only identified in XZ.

Alcohols were also abundant compounds in loquat fruit. (E)-2-hexenol contributes to loquats aromatic character; it has a green-type odour and a green-type flavour. (E)-2-hexenol, (Z)-3-hexenol and hexanol were the most abundant volatile compounds (Nakamoto, 1999). (Z)-3-hexenol and hexanol have been reported to contribute to the green aromas of loquats (Hideki et al., 1998). (Z)-2-hexenol is an important C6 compound involved in loquat aroma-flavour (Besada et al., 2013). Shaw $\&$ Wilson (1982) reported isomeric hexen-1-ols as probable contributors to loquat flavour. These fatty acid-derived short-chain volatile aldehydes and alcohols, such as hexanal, (Z)-3-hexenal, (E)-2-hexenal and (Z)-3-hexenol, are produced by enzymatic action during maceration (Chen et al., 2004). (Z)-3-hexenol, (E)-2-hexenol and hexanol were quantitatively the main alcohols found in HB1 loquat pulp. Pentanol and (E)-2-heptenol were only found in HB1, 2-hexenol was only identified in JH1, and nerol was only detected in RTBS.
Esters were also abundant compounds in loquats. Hideki et al. (1998) reported that ethyl and methyl 2-methylbutanoates are responsible for the fresh, fruity aroma of Japanese loquats. Methyl 2-methylbutanoates concentrations were significantly higher in the LQ1 and JH1 varieties.

Besada et al. (2013) reported that 2-methyl butanoic acid was the only cultivar-specific loquat compound detected in 'Algerie' among the 121 volatiles and it was not detected in the 'Golden Nugget' cultivar. However, Besada et al. (2017) showed that this compound was observed in the three new cultivars - 'Xirlero', 'Raúl' and 'Amadeo' that originated from 'Algerie', but its level was significantly lower in 'Amadeo'. 2-methyl butanoic acid was identified in LQ1 and JH1 varieties, where it was significantly higher in content than in HYS1, HB1 and XZ.

The pulp of red-fleshed loquats appears red-orange because of the abundant content of carotenoids, while the white-fleshed loquat cultivars have few carotenoids in the flesh and appear ivory. The main carotenoids accumulated in loquat flesh were $\beta$-carotene and $\beta$-cryptoxanthin (Zhou et al., 2007; Fu et al., 2012, 2014; Liu et al., 2016). In this family, the carotenoid cleavage dioxygenases (CCDs) have been shown to cleave $\beta$-carotene at the 9,10 double bond and produce the volatile apocarotenoid $\beta$-ionone, an important flower fragrance and fruit flavour (Kato, 2012). Of particular interest were apocarotenoids that possess extremely potent odour thresholds, for example $\beta$-ionone with a threshold of $0.007 \mathrm{ppb}$ (Ibdah et al., 2006). $\beta$-ionone and $\beta$-cyclocitral-oxidative degradation products from $\beta$-carotene (Lewinsohn et al., 2005) were only detected in the red-fleshed loquat varieties. Previous studies have mentioned $\beta$-ionone as contributors of the loquat flavour (Shaw \& Wilson, 1982; Hideki et al., 1998; Takahashi et al., 2000; Chen et al., 2011). Besada et al. (2013) detected high $\beta$-ionone levels in 'Golden' cultivar. Besada et al. (2017) reported that the 'Raúl' cultivar had a distinctive volatile profile characterised by high levels of $\beta$-ionone and cis-geranyl acetone. Geranyl acetone is derived from phytoene (Ibdah et al., 2006) and this compound has only been not detected in HB1. In other fruits, cis-geranylacetone has been associated with magnolia/green/floral aroma (Goldenberg et al., 2012), geranylacetone have odor thresholds of $60 \mathrm{~nL} . \mathrm{L}^{-1}$, respectively (Baldwin et al., 2000). Many of these volatile compounds, due to their low odor threshold, require only small amounts to affect a change in flavour. For instance, $\beta$-ionone is considered to be the second most important volatile contributor to tomato fruit flavour (Baldwin et al., 2000).

\subsection{Principal component analysis}

PCA was performed to identify groups among loquat varieties based on content of volatile composition of 7 cultivars (Figure 2). The results indicate that the first two principal components accounted for almost $39.7 \%$ of the total variance. The first component accounted for $22.3 \%$ of the variance, and clearly separated $\mathrm{HB} 1$ and the other six varieties due to its very high levels of aldehydes and alcohols. The second component explained approximately $16.9 \%$ of the variance. The plot of scores in the PCA analysis showed that variety HYS1 was clearly separated from the other six varieties due to its volatile profile. The volatiles of HYS1 contained 52 compounds, less than the 
average of all varieties (55 volatiles). This result was similar to that of the PCA descriptive analysis of e-nose measurements. The third component represented an additional $14.7 \%$ of the variance (Figure 3) and clearly separated LQ1, JH1, and HB1, as well as XZ, HYS1, CB1, and RTBS.
The dominant patterns present within varieties and variables are illustrated by plotting the columns of the score matrix and loading matrix, respectively (Granato et al., 2018). The loading plot of PCA revealed the relative importance of the compounds and is shown in Figure 4. The first component was a cluster of

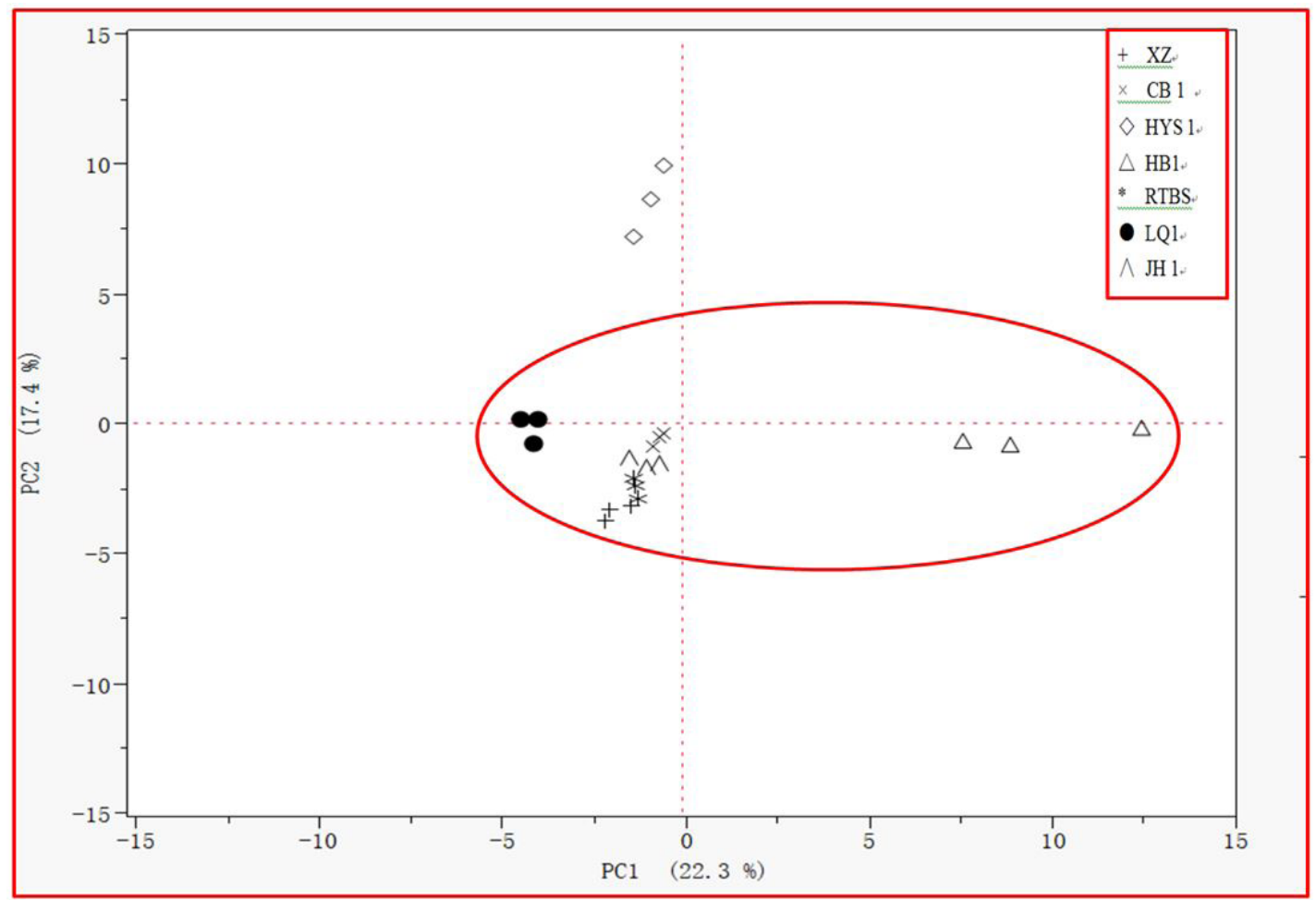

Figure 2. Principal Component Analysis score plot for the first (PC1) and second principal components (PC2). Symbols refer to variety abbreviation. HYS1, CB1, HB1 and RTBS were white-fleshed cultivars, while JH1, LQ1 and XZ were red-fleshed one, as indicated in Table 1.

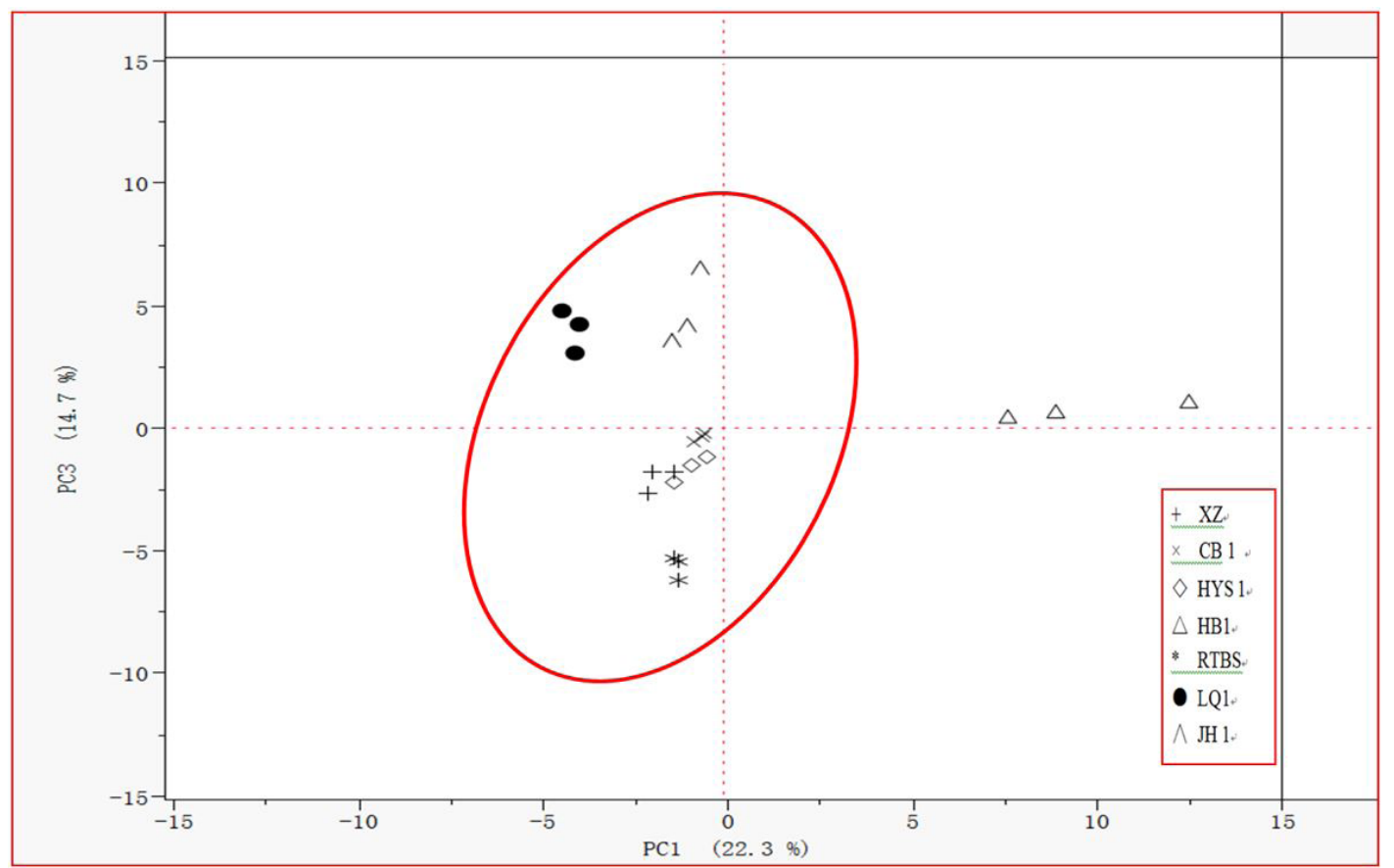

Figure 3. Principal Component Analysis score plot for the first (PC1) and third principal components (PC3). Symbols refer to variety abbreviation. HYS1, CB1, HB1 and RTBS were white-fleshed cultivars, while JH1, LQ1 and XZ were red-fleshed one, as indicated in Table 1. 
aldehyde and alcohol compounds. According to the position in the scores scatter plot of PCA, comparing the relative level between $\mathrm{HB} 1$ and the other six cultivars, significantly higher amounts of aldehydes and alcohols compounds were detected in HB1, those compounds were: hexenal, E-2-hexenal, decanal, nonanal, octanal, Z-3-hexenal, heptanal, pentanol, 1-hexenol, E-2-hexenol, Z-3-hexenol, nonanol, octanol, 1-octen-3-ol, and E-2-heptenol. The second component was characterized by a high content of terpenoids in the other six cultivars besides HYS1, including a-pinene, a-thujene, camphene, $\gamma$-terpinene, $\beta$-pinene, sabinene, $\beta$-myrcene, $\mathrm{p}$-cymene, a-terpinene, $\mathrm{D}$-limonene, terpinolene and $\beta$-phellandrene.

A plot of the scores on data of 6 cultivars except HYS1 (Figure 5, Figure 6) using first two principal components also clearly shows that HB1 is different from the others due to its

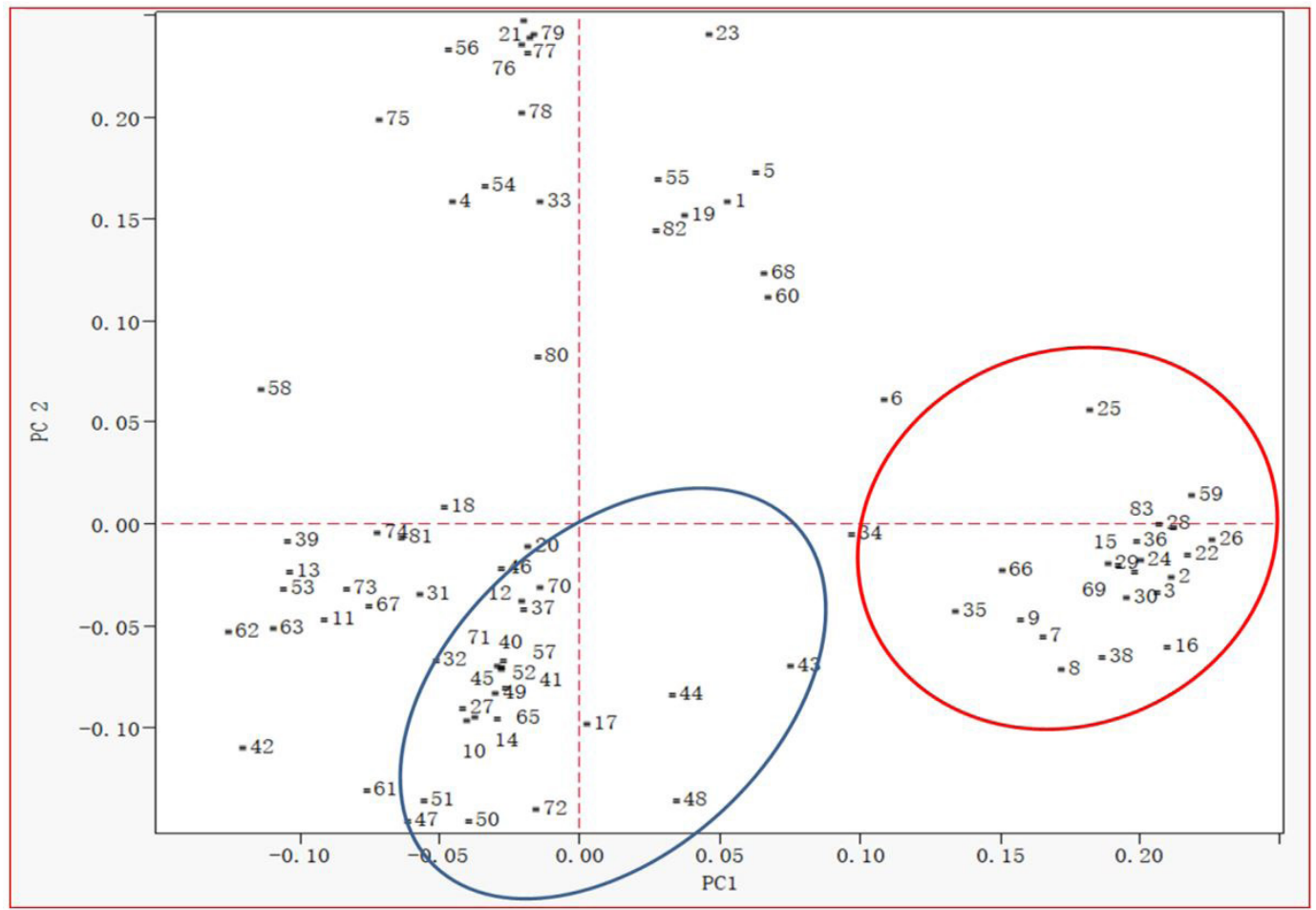

Figure 4. Principal Component Analysis loading plot for the first (PC1) and second principal components (PC2). Each number corresponds to a particular volatile compound, as indicated in Table 2.

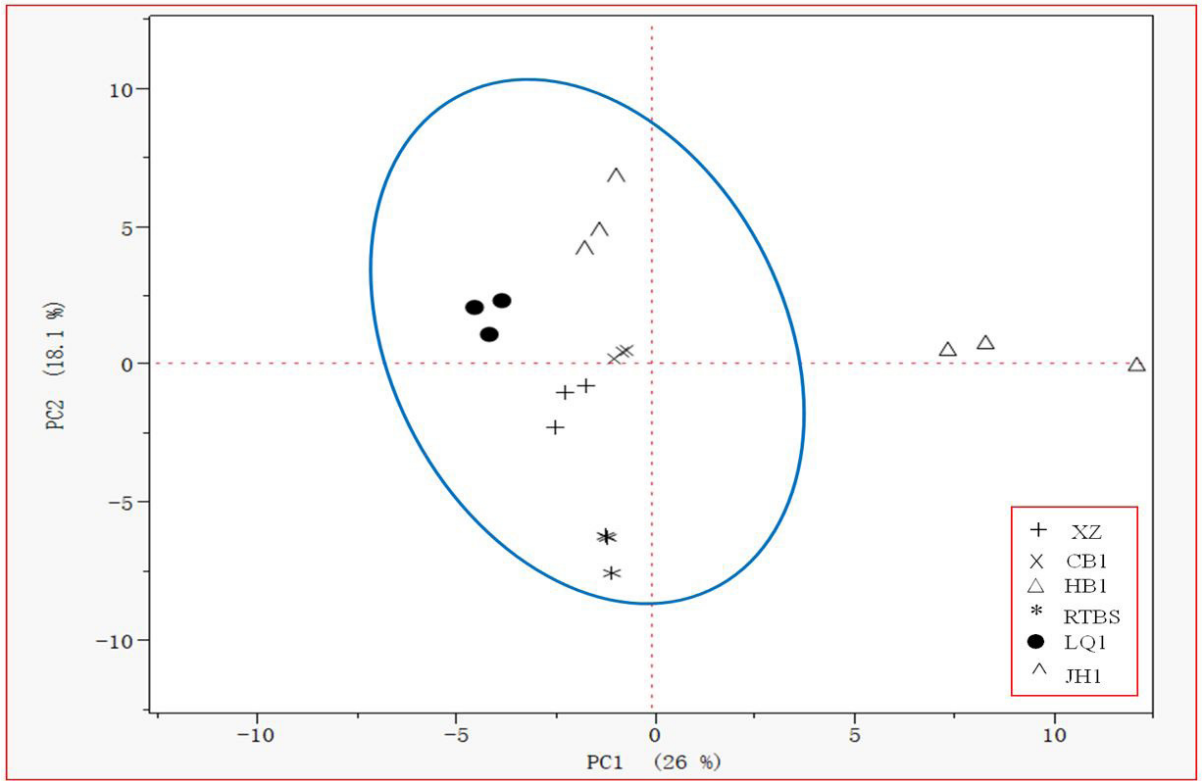

Figure 5. Principal Component Analysis score plot of 6 cultivars for the first (PC1) and second principal components (PC2). Symbols refer to variety abbreviation. CB1, HB1 and RTBS were white-fleshed cultivars, while JH1, LQ1 and XZ were red-fleshed one, as indicated in Table 1. 


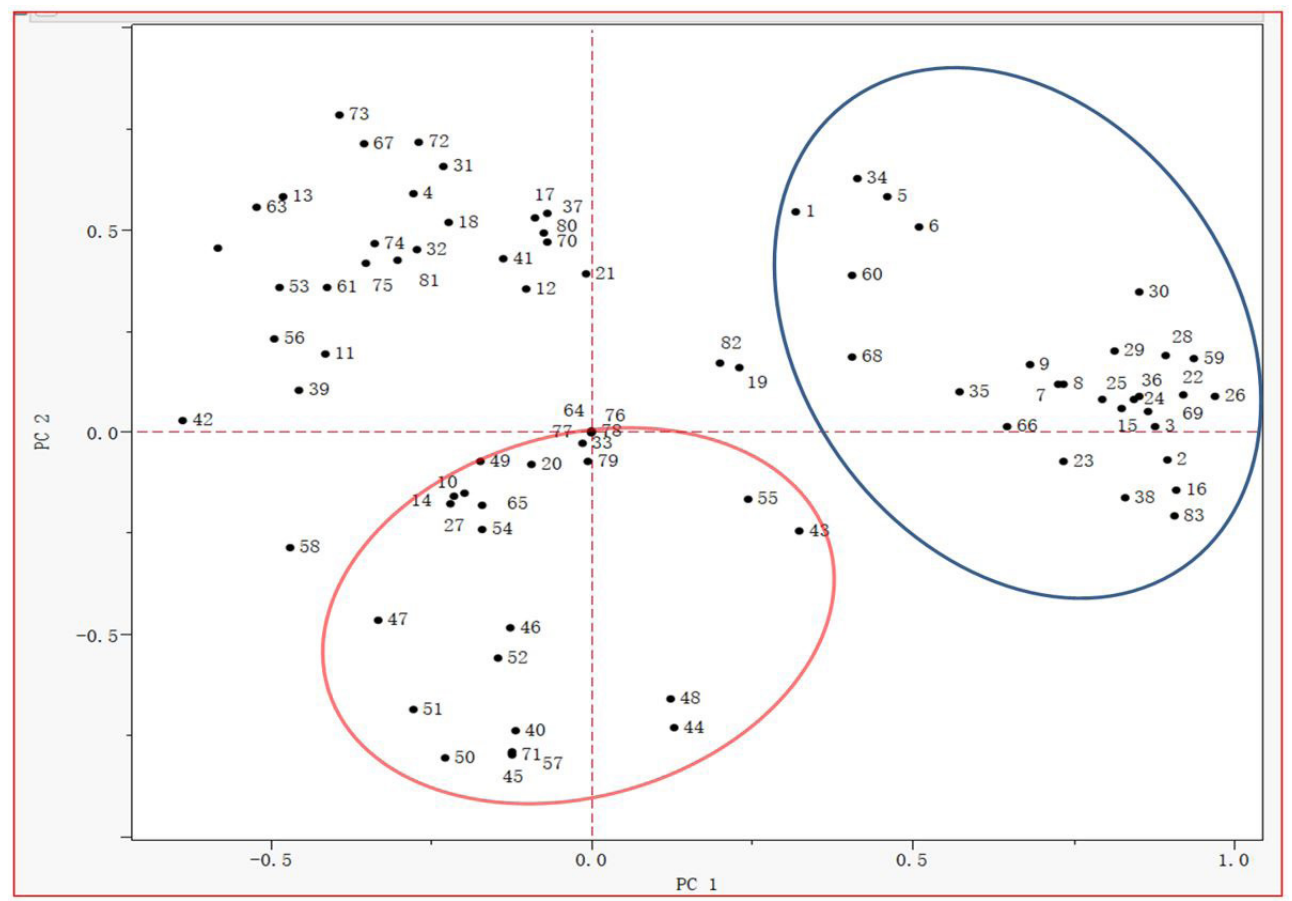

Figure 6. Principal Component Analysis loading plot of 6 cultivars for the first (PC1) and second principal components (PC2). Each number corresponds to a particular volatile compound, as indicated in Table 2.

high concentrations of aldehydes and alcohols. The second principal component obviously separated cultivars XZ, RTBS and LQ1, JH1, CB1, HB1. These two cultivars XZ and RTBS may be distinguished by their richness in high contents of terpeniods compounds, including camphene, $\gamma$-terpinene, $\beta$-myrcene, cis- $\beta$-ocimene, sabinene, $\beta$-phellandrene, $\mathrm{P}$-cymene, especially $\mathrm{D}$-limonene. The content of $\mathrm{D}$-limonene was significantly higher in XZ and RTBS. Loquat fruit is delicious, with an attractive colour, and flavour. Chen et al. (2010) noted that total soluble sugar content (TSS) and percentage of sucrose among total soluble sugars were significantly higher in white-fleshed loquat fruits than in red-fleshed ones. 7 white-fleshed loquat cultivars and 15 red-fleshed ones can be evaluated by combining chemical-physical and GC-MS analyses, the results showed that average values of fruit weight, TSS, titratable acidity (TA), invert sugar and reducing sugar were higher in white-fleshed loquat than in red-fleshed ones (Yuan et al., 2018). Although, aroma differences are generally sensed in white- and red-fleshed loquats. Principal component analysis was employed to evaluate the differences among cultivars. However, based on e-nose and GC-MS analysis, PCA could not clearly separate white-fleshed and red-fleshed loquats, our results were in accordance with Yuan et al. (2018) GC-MS research conclusion.

\section{Conclusion}

Eight-three volatiles comprising aldehydes, alcohols, terpenoids, ketones, acids, esters and other compounds were identified in four white-fleshed loquat varieties and three red-fleshed ones, among which aldehydes, alcohols, and terpenoids were quantitatively in greater abundance. D-limonene, hexanal, (E)-2-hexenal, octanal and nonanal were the most abundant volatile compounds. Only one ester-- butyl acetate was contained in 33 common compounds in seven cultivars, of which had a fruity flavor. $\beta$-ionone and $\beta$-cyclocitral, that were only detected in red-fleshed cultivars. $\beta$-ionone provided osmanthus fragrans flower like, apricot odor impact to fresh loquat aroma, $\beta$-cyclocitral contributed to a hey odorant in fresh loquat odor (Takahashi et al., 2000). The results demonstrated that PCA could not clearly separate white-fleshed and red-fleshed loquat varieties, but triploid loquats HYS1 could be discerned from diploid loquats in e-nose and GC-MS analysis. Based on volatile contents and components, the volatile profile enabled good differentiation of most loquat cultivars.

\section{Acknowledgements}

This work was supported by Fundamental Research Funds for the Central Universities (No. XDJK2015C054) and Project of Chongqing Forestry Administration (2016-10), and Project of State Forestry Administration of the P.R. China (2016-03). The authors would like to thank Qiaoli Zhang and Hongru Liu (Institute of Fruit Science, Zhejiang University, Hangzhou, China) for providing experimental help.

\section{References}

Azam, M., Jiang, Q., Zhang, B., Xu, C. J., \& Chen, K. S. (2013). Citrus leaf volatiles as affected by developmental stage and genetic type. International Journal of Molecular Sciences, 14(9), 17744-17766. http://dx.doi.org/10.3390/ijms140917744. PMid:23994837.

Baldwin, E. A., Scott, J. W., Shewmaker, C. K., \& Schuch, W. (2000). Flavor trivia and tomato aroma: biochemistry and possible mechanisms for control of important aroma components. Horticultural Science, 35, 1013-1021. 
Barboni, T., Luro, F., Chiaramonti, N., Desjobert, J. M., Muselli, A., \& Costa, J. (2009). Volatile composition of hybrids citrus juices by headspace solid-phase microextraction/gas chromatography/ massspectrometry. Food Chemistry, 116(1), 382-390. http://dx.doi. org/10.1016/j.foodchem.2009.02.031.

Besada, C., Salvador, A., Sdiri, S., Gil, R., \& Granell, A. (2013). A combination of physiological and chemometrics analyses reveals the main associations between quality and ripening traits and volatiles in two loquat cultivars. Metabolomics, 9(2), 324-336. http://dx.doi. org/10.1007/s11306-012-0447-z.

Besada, C., Sanchez, G., Gil, R., Granell, A., \& Salvador, A. (2017). Volatile metabolite profiling reveals the changes in the volatile compounds of new spontaneously generated loquat cultivars. Food Research International, 100(Pt 1), 234-243. http://dx.doi.org/10.1016/j. foodres.2017.06.068. PMid:28873683.

Capone, S., Tufariello, M., Francioso, L., Montagna, G., Casino, F., Leone, A., \& Siciliano, P. (2013). Aroma analysis by GC/MS and electronic nose dedicated to Negroamaro and Primitivo typical Italian Apulian wines. Sensors and Actuators B, Chemical, 179, 259269. http://dx.doi.org/10.1016/j.snb.2012.10.142.

Chen, F. X., Lui, X. H., Chen, L. S., \& Zheng, S. X. (2011). The determination of volatile constituents of loquat fruit and leaf by gas chromatography-mass spectrometry coupled with solid-phase microextraction. Acta Horticulturae, (887), 369-372. http://dx.doi. org/10.17660/ActaHortic.2011.887.63.

Chen, G. P., Hackett, R., Walker, D., Taylor, A., Lin, Z. F., \& Grierson, D. (2004). Identification of a specific isoform of tomato lipoxygenase (TomloxC) involved in the generation of fatty acid-derived flavor compounds. Plant Physiology, 136(1), 2641-2651. http://dx.doi. org/10.1104/pp.104.041608. PMid:15347800.

Chen, Q. Y., Zhou, J. Y., Zhang, B., Fu, X. M., Song, X. Q., Li, X., Xu, C. J., \& Chen, K. S. (2010). Sugar composition difference between white- and red-fleshed loquat fruits and its relation with activities of sucrose-metabolizing enzymes. Guoshu Xuebao, 27(4), 616-621.

Forney, C. F. (2001). Horticultural and other factors affecting aroma volatile composition of small fruit. HortTechnology, 11(4), 529-538. http://dx.doi.org/10.21273/HORTTECH.11.4.529.

Fröhlich, O., \& Schreier, P. (1990). Volatile constituents of loquat (Eriobotrya japonica Lindl.) fruit. Journal of Food Science, 55(1), 176-180. http://dx.doi.org/10.1111/j.1365-2621.1990.tb06046.X.

Fu, X. M., Feng, C., Wang, C. Y., Yin, X. R., Lu, P. J., Grierson, D., Xu, C. J., \& Chen, K. S. (2014). Involvement of multiple phytoene synthase genes in tissue and cultivar-specifc accumulation of carotenoids in loquat. Journal of Experimental Botany, 65(16), 4679-4689. http:// dx.doi.org/10.1093/jxb/eru257. PMid:24935622.

Fu, X. M., Kong, W. B., Peng, G., Zhou, J. Y., Azam, M., Xu, C. J., Grierson, D., \& Chen, K. S. (2012). Plastid structure and carotenogenicgene expression in red- and white-fleshed loquat (Eriobotrya japonica) fruits. Journal of Experimental Botany, 63(1), 341-354. http://dx.doi. org/10.1093/jxb/err284. PMid:21994170.

García-González, D. L., \& Aparicio, R. S. (2002). Sensors: from biosensors to the electronic nose. Grasas y Aceites, 53(1), 96-114. http://dx.doi. org/10.3989/gya.2002.v53.i1.293.

Goldenberg, L., Feygenberg, O., Samach, A., \& Pesis, E. (2012). Ripening attributes of new passion fruit line featuring seasonal non-climacteric behavior. Journal of Agricultural and Food Chemistry, 60(7), 18101821. http://dx.doi.org/10.1021/jf203313r. PMid:22248094.

González-Mas, M. C., Rambla, J. L., Alamar, M. C., Gutiérrez, A., \& Granell, A. (2011). Comparative analysis of the volatile fraction of fruit juice from different citrus species. PLoS One, 6(7), e22016. http://dx.doi.org/10.1371/journal.pone.0022016. PMid:21818287.
Granato, D., Putnik, P., Kovačević, D. B., Santos, J. S., Calado, V., Rocha, R. S., Cruz, A. G. D., Jarvis, B., Rodionova, O. Y., \& Pomerantsev, A. (2018). Trends in chemometrics: food authentication, microbiology, and effects of processing. Comprehensive Reviews in Food Science and Safety., 17(3), 663-677. http://dx.doi.org/10.1111/1541-4337.12341.

Hideki, N., Tomohiro, K., Tomoko, K., Masakazu, I., Tetsuo, K. (1998). Flavor components of Japanese loquat (Eriobotrya japonica Lindl.). In 42 Koryo Terupen oyobi Seiyu Kagaku ni kansuru Toronkai Koen Yoshishu (pp. 12-14). Gifu, Japan: Gifu Pharmaceutical University.

Ibdah, M., Azulay, Y., Portnoy, V., Wasserman, B., Bar, E., Meir, A., Burger, Y., Hirschberg, J., Schaffer, A. A., Katzir, N., Tadmor, Y., \& Lewinsohn, E. (2006). Functional characterization of CmCCD1, a carotenoid cleavagedioxygenase from melon. Phytochemistry, 67(15), 1579-1589. http://dx.doi.org/10.1016/j.phytochem.2006.02.009. PMid:16563447.

Jia, M. Y., Zhang, Q. H., \& Min, D. B. (1998). Optimization of solidphase microextraction analysis for headspace flavor compounds of orange juice. Journal of Agricultural and Food Chemistry, 46(7), 2744-2747. http://dx.doi.org/10.1021/jf971020w.

Jiang, J. M., Hu, W. S., Xu, Q. Z., Chen, X. P., Deng, C. J., Jiang, F., \& Zheng, S. Q. (2014). Volatiles in fruits of two loquat cultivars Xiangtian, Jiefangzhong and their two offspring selections. Zhiwu Yichuan Ziyuan Xuebao, 15(4), 894-900.

Kato, M. (2012). Mechanism of carotenoid accumulation in citrus fruit. Journal of the Japanese Society for Horticultural Science, 81(3), 219-233. http://dx.doi.org/10.2503/jjshs1.81.219.

Lewinsohn, E., Sitrit, Y., Bar, E., Azulay, Y., Ibdah, M., Meir, A., Yosef, E., Zamir, D., \& Tadmor, Y. (2005). Not just colors: carotenoid degradation as a link between pigmentation and aroma in tomato and watermelon fruit. Trends in Food Science \& Technology, 16(9), 407-415. http://dx.doi.org/10.1016/j.tifs.2005.04.004.

Liu, X. H., Sun, H. Y., Chen, W. W., Guo, Q. G., Li, X. L., \& Liang, G. L. (2016). Advances in studies on carotenoids in loquat fruit. Guoshu Xuebao, 33(7), 874-881.

Nakamoto, H. (1999). Flavor components of Japanese loquat fruit. Koryo, 203, 109-116.

Peris, M., \& Escuder-Gilabert, L. (2009). A 21st century technique for food control: electronic noses. Analytica Chimica Acta, 638(1), 1-15. http://dx.doi.org/10.1016/j.aca.2009.02.009. PMid:19298873.

Pino, J. A., Marbot, R., \& Vazquez, C. (2002). Characterization of volatiles in Loquat fruit (Eriobotryajaponica Lindl.). Revista CENIC Ciencias Químicas, 33(3), 115-119.

Reinhard, H., Sager, F., \& Zoller, O. (2008). Citrus juice classification by SPME-GC-MS and electronic nose measurements. LebensmittelWissenschaft + Technologie, 41(10), 1906-1912. http://dx.doi. org/10.1016/j.lwt.2007.11.012.

Ren, J. N., Tai, Y. N., Dong, M., Shao, J. H., Yang, S. Z., Pan, S. Y., \& Fan, G. (2015). Characterisation of free and bound volatile compounds from six different varieties of citrus fruits. Food Chemistry, 185, 25-32. http://dx.doi.org/10.1016/j.foodchem.2015.03.142. PMid:25952837.

Shaw, P. E., \& Wilson, C. W. (1982). Volatile constituents of loquat (Eriobotrya japonica Lindl.) fruit. Journal of Food Science, 47(5), 1743-1744. http://dx.doi.org/10.1111/j.1365-2621.1982.tb05028.x.

Solis-Solis, H. M., Calderon-Santoyo, M., Gutierrez-Martinez, P., Schorr-Galindo, S., \& Ragazzo-Sanchez, J. A. (2007). Discrimination of eight varieties of apricot (Prunusarmeniaca) by electronic nose, LLE and SPME using GC-MS and multivariate analysis. Sensors and Actuators. B, Chemical, 125(2), 415-421. http://dx.doi.org/10.1016/j. snb.2007.02.035. 
Su, M. S., Zhang, B., Ye, Z. W., Chen, K. S., Guo, J., Gu, X. J., \& Shen, J. Y. (2013). Pulp volatiles measured by an electronic nose are related to harvest season, TSS concentration and TSS/TA ratio among 39 peaches and nectarines. Scientia Horticulturae, 150, 146-153. http:// dx.doi.org/10.1016/j.scienta.2012.10.020.

Takahashi, H., Sumitani, H., Inada, Y., Mori, D., \& Nakano, Y. (2000). Potent aroma volatiles in fresh loquat and its canned product. Nippon Shokuhin Kagaku Kogaku Kaishi, 47(4), 302-310. http:// dx.doi.org/10.3136/nskkk.47.302.

Wilson, A. D., \& Baietto, M. (2009). Applications and advances in electronic-nose technologies. Sensors, 9(7), 5099-5148. http://dx.doi. org/10.3390/s90705099. PMid:22346690.

Wu, D., Fan, W. G., He, Q., Guo, Q. G., Spano, A. J., Wang, Y., Timko, M. P., \& Liang, G. L. (2015). Genetic diversity of loquat [Eriobotrya japonica (Thunb.) Lindl.] native to Guizhou Province (China) and its potential in the genetic improvement of domesticated cultivars. Plant Molecular Biology Reporter, 33(4), 952-961. http://dx.doi. org/10.1007/s11105-014-0809-y.

Yuan, T., Chen, W. W., Sun, H. Y., Yang, H. P., Liang, G. L., \& Guo, Q. G. (2018). Analysis of the volatile components in loquats with different flesh colors. Shipin Kexue, 39(24), 209-217.

Zhang, B., Yin, X. R., Li, X., Yang, S. L., Ferguson, I., \& Chen, K. S. (2009). Lipoxygenase gene expression in ripening kiwifruit in relation to ethylene and aroma production. Journal of Agricultural and Food Chemistry, 57(7), 2875-2881. http://dx.doi.org/10.1021/ jf9000378. PMid:19334761.

Zhou, C. H., Xu, C. J., Sun, C. D., Li, X., \& Chen, K. S. (2007). Carotenoids in white-and red-fleshed loquat fruits. Journal of Agricultural and Food Chemistry, 55(19), 7822-7830. http://dx.doi.org/10.1021/ jf071273h. PMid:17708644. 